\title{
Um estudo regional dos determinantes da geração de renda e construção da cidadania nos Projetos de Assentamentos
}

\author{
Paulo Aguiar do Monte ${ }^{1}$ \\ Ana Elizabete da Silva Pereira²
}

Resumo: Este trabalho analisa a influência de determinados fatores (capital social, tempo de existência e as etapas do Projeto de Assentamento) na renda total gerada em cada assentamento do País. Embora os Projetos de Assentamento apresentem uma metodologia nacional, procurou-se dar um enfoque regional ao estudo, devido às diferentes realidades observadas. Através das análises pode-se observar que nas regiões do Eixo Sul, principalmente Sudeste e Sul, existe um grande número de PAs consolidados e é maior a participação ativa das famílias em cooperativas, reflexo da maior capacidade de organização e da maior escolaridade dessas pessoas. Tal fato pode estar influenciando diretamente no desenvolvimento de etapas fundamentais dos Projetos, haja vista que nestas regiões são também foram observadas as maiores rendas geradas.

Palavras-chaves: reforma agrária, assentamento, renda.

Abstract: This paper analyses the influence of determinant factors (social capital, lifetime of the project and the stages of the Settlement Projects (PA)) in the total income generated in each settlement of Brazil. Although the Settlement Projects have a national methodology, we try to do a regional approach for the different situations observed. Through the analysis can be seen that both east and south of Brazil have a higher number of PA's established and an active participation of families in the cooperatives, reflecting the level of organization and more education of these families. This fact may be directly influencing the development of these projects, considering that these regions are also shown as the upper incomes.

Key-words: Settlement Project, agrarian reform, income.

Classificação JEL: R52, R28, O18.

\footnotetext{
${ }^{1}$ Professor Adjunto da Universidade Federal da Paraíba. Doutor em Economia pelo Pimes/UFPE, 2005. E-mail: pauloaguiardomonte@gmail.com

2 Professora da Faculdade Boa Viagem. Mestre em Administração e Comunicação Rural UFRPE, 2002. E-mail: elizabete_101@hotmail.com
} 
Um estudo regional dos determinantes da geração de renda e construção da cidadania nos Projetos de Assentamentos

\section{Introdução}

Nos últimos anos, a questão agrária permeou os processos de busca de desenvolvimento no Brasil. Embora suas origens remontem à época do período colonial (século XVI), quando o País foi dividido em grandes latifúndios - as capitanias hereditárias - a discussão acerca do uso racional da terra, transformando-a em um espaço habitado e produtivo ganhou maior destaque no século XIX, principalmente nos anos 80 e 90, quando o processo de formação de novas áreas de assentamentos rurais foi intensificado no Brasil.

A luta pela conquista de terras sempre foi marcada pelos conflitos pela posse da terra, por conta da estrutura fundiária brasileira, altamente concentrada ${ }^{3}$. É neste contexto que se inserem os movimentos sociais organizados. Foi por meio destes movimentos, em especial, da organização sindical de trabalhadores rurais assalariados no corte da cana e dos trabalhadores rurais sem terra que, nos anos 80, intensificou-se o movimento pela Reforma Agrária no Brasil ${ }^{4}$.

De forma geral, as propostas elaboradas para a reforma agrária visam, além da divisão de terras, todo um esforço na elaboração de Políticas Públicas que objetivam incluir as famílias de assentados num processo de busca pela cidadania. Neste caso, a divisão de terras deve vir atrelada a outras ações, como: apoio à educação, formação técnica, financiamento com juros baixos, programa de inclusão da mulher ao trabalho no assentamento, construção do pensamento voltado para ações ambientais e consciência dos direitos do cidadão. Para Leite (1995), os assentamentos promovem diferentes mudanças no território, como as que são ligadas ao poder local, às questões relacionadas à participação política e formação de políticas públicas, às formas de organização social e produtiva e às questões ambientais.

Entretanto, na prática, ainda existem certas barreiras, seja na questão político-distributiva seja no aspecto técnico à implementação da Reforma Agrária no Brasil. Em estudo realizado pelo Ipea (Instituto de Pesquisas Econômica Aplicada) sobre o Procera (Programa de Crédito para a Reforma Agrária), Resende (1999) observou que durante a concessão do crédito houve um aumento na compra de eletrodomésticos e animais para criação, identificando a ineficácia do Programa ao objetivo do empréstimo fornecido, visto que pouco contribuiu

\footnotetext{
${ }^{3}$ Para Freire (1992), os latifúndios imensos, sem produzir e sem gente, de propriedade de uma só família, vêm impedindo que se faça no País uma divisão mais humana e mais racional que, aliás, jamais se ensaiou com seriedade, dessas terras.

${ }^{4}$ A reforma agrária veio como uma opção para solucionar o problema da pobreza no campo. Entretanto, essa possibilidade não agradou os proprietários de latifúndios que passaram a reprimir os movimentos populares que tinham esse objetivo, como foi o caso das Ligas Camponesas (Oliveira, 2001).
} 
para a melhoria da produção e, conseqüente, emancipação do assentado. Segundo o referido autor, constatou-se os desvios dos recursos para outros fins, ao invés da modernização dos meios de produção, o que dificulta sua evolução econômica e independência da tutela do Estado. Em outra pesquisa, Buanain, Silveira e Teófilo (2001) enfocam a necessidade de um conjunto de atuações técnicas e a importância dos grandes grupos de assentamentos. Para eles, o desenvolvimento da agricultura familiar requer o apoio de um conjunto de serviços técnicos especializados, além de equipamentos apropriados à sua escala e sistemas de produção. Os autores ressaltam, ainda, a necessidade da formação crítica destes agricultores, para que estes funcionem como sementes de proliferação de ideais de cidadania e trabalho junto aos outros agricultores.

Apesar dos obstáculos, tem-se observado que, nos últimos anos, o Poder Público vem tendo uma preocupação maior em não apenas distribuir as terras, mas, oferecer condições ao agricultor de sobreviver dela, promovendo ações que criem/fortaleçam o capital social e aperfeiçoando as etapas do Projeto de Assentamento (PA). Os assentamentos estão apoiados por uma política de crédito própria, por meio do Incra (Instituto Nacional de Colonização e Reforma Agrária), que financia a implantação dos lotes, com recursos para a construção da moradia, da manutenção da família no primeiro ano, além de financiar o custeio da produção e disponibilizar crédito para investimento, com prazos e carências.

Neste contexto, este trabalho tem como objetivo discutir as etapas dos Projetos de Assentamento, em especial, o engajamento em cooperativas e associações (capital social), o tempo de criação do Projeto de Assentamento e o desenvolvimento de suas etapas. Desta forma, procurar-se-á identificar uma possível melhoria na qualidade de vida das pessoas através da importância destes fatores no processo de geração de renda e construção da cidadania. As informações foram baseadas em dados do Censo da Reforma Agrária, 2002, contemplando todo o Brasil.

Além desta introdução, este artigo está dividido em mais seis seções. A seção dois é dedicada à análise de fatores determinantes para o desenvolvimento sustentável do assentamento. A terceira seção traz a metodologia (procedimentos econométricos para estimar a importância dos fatores na determinação da renda total gerada pelas famílias assentadas). Na seção 4 é feita uma análise regional e descritiva dos Projetos de Assentamento. Na quinta seção estão contidos os resultados da análise econométrica. Por fim, a última seção contempla as considerações finais. 
1026 . Um estudo regional dos determinantes da geração de renda e

construção da cidadania nos Projetos de Assentamentos

\section{Fatores determinantes para o desenvolvimento do Assentamento}

Atualmente, as Políticas Públicas voltadas para a reforma agrária procuram incluir os conceitos de desenvolvimento local, entendido aqui não apenas como a distribuição de terras, mas a preparação do agricultor, e da comunidade como um todo, para a produção e desenvolvimento do seu negócio visando se tornar um cidadão independente do Estado.

Dentre os fatores críticos de sucesso para o desenvolvimento sustentável ${ }^{5}$ do assentamento podem-se enumerar três, em especial: fortalecimento do capital social, tempo de criação do projeto de assentamento e o desenvolvimento das etapas do projeto de assentamento. Estes fatores, atuando conjuntamente, tendem a trazer benefícios para os assentamentos.

\subsection{Capital Social}

O capital social é uma variável de extrema importância para o sucesso de um Projeto de Assentamento. Nele estão contidas normas de confiança mútua e de comportamento em vigor.

No contexto deste artigo, capital social será visto como um elemento estratégico fundamental para avaliar a sustentabilidade e o desenvolvimento dos Projetos de Assentamento dado que envolve uma soma de atributos (confiança, solidariedade, respeito às normas) importantes para a organização da vida social da população de assentados.

Para Putnam (2000), o capital social fortalece a execução de ações que beneficiam a comunidade, e sua ausência tende a representar um enfraquecimento das características de organização social, vitais para o desenvolvimento de determinadas ações que visam aumentar a eficiência da comunidade nele envolvido. Jara (1999) e Lazarini, Chaddad e Neves (2006) mostram que o capital social influencia diretamente no desenvolvimento regional de determinadas comunidades/regiões, principalmente em naquelas desfavorecidas de capital físico, financeiro e humano, sendo, portanto, um bom substituto para essa escassez desses atributos.

${ }^{5}$ Embora não seja objetivo deste estudo a discussão acerca do desenvolvimento sustentável, cabe-nos ter ciência da definição dada pela Comissão Mundial sobre Meio Ambiente e Desenvolvimento (CMMAD, 1988) acerca do seu conceito: "desenvolvimento sustentável é o desenvolvimento que satisfaz as necessidades da geração presente sem comprometer as possibilidades das futuras gerações em satisfazer as suas necessidades". 


\subsection{Tempo de criação do Projeto de Assentamento (PA)}

Para o desenvolvimento sustentável de qualquer organização social, a maturação da concepção de ideais comuns é fator importante para o seu desenvolvimento enquanto organização coletiva visto que representa a passagem e o aprendizado de fases anteriores vencidas.

É de se esperar que em assentamentos com maior tempo de existência possa existir uma melhor condição de socialização dos agentes envolvidos, de desenvolvimento humano, de responsabilidade e deveres, de condições de infra-estrutura e de fortalecimento capital social existente. Segundo Carvalho (1994), em estudo restrito aos assentamentos no estado de São Paulo, o tempo relativamente curto da existência de alguns assentamentos é variável significante das causas da diferença de desenvolvimento existente entre os assentamentos. Isto ocorre em função de, na maioria dos casos, os assentamentos mais antigos dispor de melhor infra-estrutura (rede de energia elétrica, sistema sanitário, associações, cooperativas) em relação aos mais recentes. Ademais, devem-se levar em consideração, também, que determinadas peculiaridades e condicionantes socioeconômicos operam de forma diferente ao longo dos anos.

\subsection{O desenvolvimento das etapas do Projeto de Assentamento}

O objetivo final da reforma agrária é tornar o beneficiário do Projeto de Assentamento independente e capacitado para continuar desenvolvendo sua própria atividade, em busca da estabilidade social e da conquista da cidadania, tornando-o sujeito do desenvolvimento sustentável rural. Para chegar a esse objetivo, o PA deve seguir algumas etapas, dentre as quais ${ }^{6}$ :

1. Elaboração do Plano de Desenvolvimento do Assentamento (PDA). O PDA é o planejamento de um modelo de gestão de agricultura familiar coletiva, no qual os projetos são realizados por meio de técnicas de participação das famílias, tornando os assentados mais envolvidos com a proposta de desenvolvimento e mais comprometidos com as metas e os objetivos coletivos.

2. Concessão de crédito. Representa o auxílio financeiro para a construção das residências e da estrutura básica de sobrevivência no assentamento. Essa etapa tem a finalidade de proporcionar a complementação do crédito às

\footnotetext{
${ }^{6}$ As etapas que estão descritas neste artigo formam o esboço principal de todas as fases de um Projeto de Assentamento. Portanto, não se tem o interesse de descrever todas as fases detalhadamente, apenas de mostra - de forma resumida - o escopo do projeto de assentamento.
} 
1028 . Um estudo regional dos determinantes da geração de renda e construção da cidadania nos Projetos de Assentamentos

famílias assentadas, visando provê-las dos recursos necessários a sua instalação nos Projetos de Assentamentos.

3. Implantação completa da infra-estrutura. Aqui, os PAs devem se organizar buscando infra-estrutura como: estradas vicinais, rede elétrica, saneamento básico, sistema de captação e distribuição de água. Outra atividade desenvolvida é a formação de parcerias que propiciem ao município apoiá-los na elaboração de planos de ocupação, abertura de ruas, fornecimento de água, energia elétrica e saneamento básico para as casas, atendimento à saúde e funcionamento das escolas.

4. Financiamento e auxílio técnico (Procera ou Pronaf - Programa Nacional de Fortalecimento da Agricultura Familiar). Esta etapa objetiva o incremento de renda dos Projetos de Assentamentos rurais por meio de atividades econômicas sustentáveis, valorizando as características regionais, experiências e potencialidades locais. Para o êxito desta ação é fundamental o apoio à implantação e à recuperação da agroindústria, contratação de assessoria técnica, capacitação multiplicadora (agricultores e técnicos), apoio às ações de inserção mercadológica da produção dos assentados, apoio à realização de pesquisas de mercado, apoio à divulgação e venda dos produtos da reforma agrária.

5. Consolidação do Projeto de Assentamento. Para a conclusão desta fase, é necessário entregar a titulação, concessão e destinação de imóveis rurais. Essa ação tem a finalidade de transferir, em definitivo, aos assentados o domínio das terras destinadas a projetos de assentamentos e regularização fundiária.

\section{Aspectos metodológicos e caracterização da amostra}

O sucesso nas etapas da realização de um PA pode ser medido por meio da construção de bases sólidas de desenvolvimento local sustentável e da conquista definitiva da cidadania, vitais para diminuição da pobreza e o desenvolvimento do País. ${ }^{7}$

Uma questão empírica crucial é estimar em que medida determinadas fatores influencia na geração de renda em um Projeto de Assentamento. No caso deste estudo, a discussão empírica é conduzida segundo duas vertentes: uma relativa às disparidades regionais (análise descritiva) e outra voltada para a importância do capital social, do tempo de criação dos assentamentos e das fases de um PA na determinação da renda total gerada pelas famílias (análise estatística e econométrica).

${ }^{7}$ A cidadania aqui é entendida como um conjunto de direitos que o indivíduo tem que lhe permitem participar direto ou indiretamente das organizações do Estado e de sua administração. 
A análise estatística será feita através do teste da igualdade de médias (Anova), aplicado para verificar se a diferença de renda observada entre etapas do PA é estatisticamente significativa, enquanto a análise econométrica será feita por meio da estimação do modelo de regressão múltipla, tendo como variável dependente a renda total gerada pelas famílias, somando tudo o que elas ganham, produzem ou tem de benefícios e, como variáveis explanatórias, os fatores que visam à emancipação do assentamento ${ }^{8}$.

O modelo de regressão múltipla é definido como:

$$
Y_{i}=\alpha_{i}+\sum \beta_{i} X_{i}+\varepsilon_{i}
$$

em que $Y_{i}=$ Variável dependente; $\alpha_{i}=$ coeficiente linear; $\beta_{i}=$ coeficientes das variáveis independentes; $X_{i}=$ variáveis independentes; $\varepsilon_{i}=$ erro aleatório.

Assim, a variação da renda será explicada pelas seguintes variáveis indicadores: PDA já elaborado (variável indicadora que assume valor 1 (um) se o PDA fora elaborado e valor 0 (zero) caso contrário); Crédito de aquisição de material de construção total/parcial concedido (variável indicadora que assume o valor 1 (um) se o crédito de aquisição de material de construção total/parcial concedido e 0 (zero), caso contrário); Infra-estrutura básica já implantada (variável indicadora que assume o valor 1 (um) se a infra-estrutura básica já está implantada e 0 (zero), caso contrário); Acesso ao Pronaf/Procera; total ou parcialmente concedido (variável indicadora que assume o valor 1 (um) se as famílias tiveram acesso ao crédito do Pronaf/Procera e 0 (zero), caso contrário); PA consolidado (variável indicadora que assume o valor 1 (um) se o PA está consolidado e 0 (zero), caso contrário); Região do País (variáveis indicadoras: região Norte, região Centro-Oeste, região Sudeste e região Sul; sendo a região Nordeste usada como referência); Anos de existência do PA (variável contínua, em anos) ${ }^{9}$; Participação ativa em associações (variável contínua obtida através da divisão entre participação ativa em associações e número de membros da família em casa assentamento); Participação ativa em cooperativas (variável contínua obtida por meio da divisão entre participação ativa em cooperativas e número de membros da família em cada assentamento). ${ }^{10}$

Portanto, a equação de cada modelo estudado será representada por 12 (doze) variáveis indicadoras - estimando-se 13 parâmetros, incluindo o termo constante -, cujo objetivo será verificar, em função da renda total gerada pelas

\footnotetext{
${ }^{8}$ Devido às informações contidas no questionário, foi considerada a renda total auferida somando tudo o que as famílias ganham, produzem ou têm de benefícios, uma proxy da renda gerada no assentamento.

${ }^{9}$ No censo da Reforma Agrária, a data da criação do PA está em calendário juliano. No entanto, para esta análise foi transformado com base no calendário gregoriano.

${ }^{10}$ No caso do uso de variáveis indicadoras (dummy), para evitar a perfeita colinearidade com as variáveis categóricas (a chamada armadilha da dummy), foi necessário excluir uma variável categórica da estimação (variável base).
} 
famílias, o impacto de cada uma das diferentes variáveis consideradas importantes para o desenvolvimento do Projeto de Assentamento. Ademais, serão estimadas mais cinco regressões, uma para cada região do Brasil; neste caso, a equação de cada modelo estudado será representada por oito variáveis indicadoras - estimando-se nove parâmetros, incluindo o termo constante.

A base de dados utilizada é oriunda de informações primárias do Banco de Dados do Censo da Reforma Agrária (2002), disponível na homepage do CIS (Consórcio de Informações Sociais). Só foram considerados para a amostra deste estudo os questionários respondidos pelo empreendedor social [responsável pelo PA ou Funcionário do Incra que conhece o PA].

\section{Análise regional e descritiva dos Projetos de Assentamento}

A análise descritiva deste trabalho optou por realizar um estudo regional dos Projetos de Assentamento (PA) no País, com o intuito de apresentar uma melhor compreensão e dimensão das etapas de um PA no contexto regional. Ao todo foram considerados 4.353 questionários, divididas de acordo com a região do País onde se situa o Projeto de Assentamento, conforme distribuição a seguir: região Norte (909 observações), Nordeste (1.955 observações), Centro-Oeste (591 observações), Sudeste (372 observações) e Sul (526 observações).

A Tabela 1 contém informações sobre o número total de municípios, número de famílias (morando no PA em casas individuais) ${ }^{11} \mathrm{e}$ área total dos Projetos de Assentamento (em ha), por região do País. Com isso, podem ser feitas duas importantes observações:

1. O Nordeste detém o maior número de municípios (623) e de famílias morando em casas individuais $(175.350)^{12}$. Historicamente, é a região que possui o maior número de famílias assentadas. Informações do Incra mostram que, até 1996, o percentual de famílias assentadas no Nordeste e Norte, em relação ao total do País, era de 38,1 e de 35,8 , respectivamente. Neste estudo, este percentual variou para 37,6 e 33,2 , respectivamente.

\footnotetext{
${ }^{11}$ Como o número de famílias que não moram no Projeto de Assentamento, mas que usufrui do mesmo é bastante reduzido em relação ao total de famílias (aproximadamente 0,5\%). Sendo assim, foram consideradas para análise as famílias que moram nos respectivos PAs.

${ }^{12}$ O número de municípios contemplados com Projetos de Assentamento, por estado da Federação, foi: Amazonas (22), Acre (20), Amapá (13), Pará (74), Rondônia (37), Roraima (9), Tocantins (75), Alagoas (29), Bahia (107), Ceará (83), Maranhão (117), Pernambuco (69), Paraíba (68), Piauí (56), Rio Grande do Norte (62), Sergipe (32), Espírito Santo (26), Minas Gerais (72), Mato Grosso do Sul (44), Mato Grosso (91), Goiás (65), São Paulo (52), Rio de Janeiro (20), Paraná (100), Santa Catarina (40) e Rio Grande do Sul (43).
} 
2. A região Norte apresentou o maior volume de área destinada aos Projetos de Assentamentos. As áreas desapropriadas são determinadas por meio de estudos técnicos (topográficos) e de informações sobre os imóveis rurais (latifúndio ou minifúndio improdutivos). Segundo o Incra, as áreas improdutivas são comum nesta região onde, em 2005, aproximadamente $80 \%$ da área total destinada à reforma situava-se no Norte do Brasil. Entretanto, embora os assentamentos não apresentem uma distribuição geográfica uniforme sobre o conjunto do território nacional em termos quantitativos $^{13}$, em relação à área média (em ha), percebe-se que os Projetos possuem dimensões territoriais bastante próximas.

Tabela 1. Brasil. Número total de municípios, número de famílias e área total dos Projetos de Assentamento (PA), por Região do País, 2002.

\begin{tabular}{lcccc}
\hline Regiões & Municípios & Famílias & $\begin{array}{c}\text { Área } \\
\text { Total (ha) }\end{array}$ & $\begin{array}{c}\text { Área } \\
\text { Média (ha) }\end{array}$ \\
\hline Norte & 213 & 155.350 & 13.550 .683 & $35.358,93$ \\
Nordeste & 623 & 175.584 & 5.296 .921 & $35.540,85$ \\
Centro-Oeste & 200 & 81.373 & 5.484 .915 & $35.370,75$ \\
Sudeste & 170 & 28.587 & 1.053 .783 & $35.451,98$ \\
Sul & 183 & 25.895 & 542.936 & $35.032,09$ \\
Total & 1.389 & 466.789 & 25.929 .238 & $35.410,70$ \\
\hline
\end{tabular}

Fonte: Elaboração própria a partir do Banco de Dados do Censo da Reforma Agrária, 2002, Módulo Projetos.

A Tabela 2 complementa a anterior ao analisar dois aspectos importantes da caracterização dos PAs: o tempo de existência (em anos) e o capital social. Conforme informações contidas na primeira linha da tabela, percebe-se que os assentamentos diferem-se entre si em termos do tempo de criação; os localizados no Nordeste possui um tempo médio de oito anos enquanto os existentes nas regiões Sul e Sudeste tem 12 anos, de média, de existência. No que concerne à participação ativa das famílias em associações e cooperativas - capital social - fica clara a desigualdade regional. Enquanto no Norte/Nordeste do País a participação é quase absoluta em associações e mínima em cooperativas, no Eixo Sul do País a situação é a contrária. Mais de $41 \%$ dos assentamentos participam ativamente de cooperativas, número que reduz para apenas $6,5 \%$ no Nordeste e $4,5 \%$ no Norte, demonstrando a diferença de comportamento social entre os assentamentos.

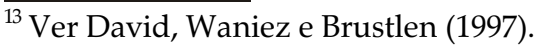


1032 - Um estudo regional dos determinantes da geração de renda e construção da cidadania nos Projetos de Assentamentos

Tabela 2. Brasil. Características dos assentamentos por região do País, 2002

\begin{tabular}{lccccc}
\hline $\begin{array}{l}\text { Características dos } \\
\text { Assentamentos / Região }\end{array}$ & Norte & Nordeste & $\begin{array}{c}\text { Centro- } \\
\text { Oeste }\end{array}$ & Sudeste & Sul \\
\hline Anos de existência do PA & 11,3 & 8,21 & 8,06 & 11,95 & 12,61 \\
$\begin{array}{l}\text { Participação ativa } \\
\text { em associações (\%) }\end{array}$ & 97,4 & 96,5 & 94,1 & 67,7 & 42,6 \\
$\begin{array}{l}\text { Participação ativa } \\
\text { em Cooperativas (\%) }\end{array}$ & 4,4 & 6,5 & 16,2 & 12,4 & 41,4 \\
\hline
\end{tabular}

Fonte: Elaboração própria a partir do Banco de Dados do Censo da Reforma Agrária, 2002, Módulo Projetos.

Após a visão geral da amostra selecionada, o estudo centrará seu foco em cinco importantes etapas: PDA já elaborado; Crédito de aquisição de material de construção total/parcial concedido; Infra-estrutura básica já implantada; Acesso ao Pronaf/Procera; total ou parcialmente concedido e PA consolidado. Na Tabela 3 estão descritas essas etapas e o percentual de projetos de assentamento que se encontra em cada uma delas.

Inicialmente, observa-se que o acesso ao Pronaf/Procera e ao crédito de aquisição de material de construção atinge um percentual maior de assentamentos comparativamente às demais fases do Projeto. A etapa com menor percentual é a PA consolidado (com apenas 4,4\% no Nordeste), explicada por ser justamente uma das últimas etapas do Projeto. Outra informação importante é a seqüência lógica das etapas do processo. Ao se fazer uma relação com as regiões do País, percebe-se que nas fases mais avançadas do Projeto, as regióes do Centro-Sul detêm os maiores índices de Projetos. Como exemplo, pode-se citar as fases PDA já elaborado, Infra-estrutura básica já implantada e acesso ao Pronaf/Procera em que tais regiões (Sudeste e Sul) apresentaram a maior participação relativa de Projetos nestas etapas, que são fundamentais para que as famílias possam estabelecer as atividades de produção de acordo com a potencialidade local visando o desenvolvimento do assentamento.

Tabela 3. Brasil. Projetos de Assentamento (PA) por fase do Projeto e Região do País, em percentual, 2002

\begin{tabular}{lccccc}
\hline Etapas / Região & Norte & Nordeste & $\begin{array}{c}\text { Centro- } \\
\text { Oeste }\end{array}$ & Sudeste & Sul \\
\hline PDA já elaborado & 27,9 & 27,6 & 22,5 & 43,0 & 62,7 \\
$\begin{array}{l}\text { Crédito de aquisição de material de } \\
\text { construção total/parcial concedido }\end{array}$ & 80,0 & 84,5 & 81,4 & 59,9 & 91,4 \\
$\begin{array}{l}\text { Infra-estrutura básica já implantada } \\
\text { Acesso ao Pronaf/Procera total }\end{array}$ & 13,4 & 25,3 & 33,7 & 40,9 & 45,8 \\
$\begin{array}{l}\text { ou parcialmente concedido } \\
\text { PA consolidado }\end{array}$ & 55,6 & 49,7 & 82,9 & 82,3 & 89,7 \\
\hline
\end{tabular}

Fonte: Elaboração própria a partir do Banco de Dados do Censo da Reforma Agrária, 2002, Módulo Projetos. 


\section{A importância dos fatores de sucesso na determinação da renda total gerada pelas famílias: uma análise econométrica}

A segunda vertente do estudo se preocupará em investigar a importância de determinados fatores na geração de renda das famílias assentadas. Primeiramente, no intuito de se avaliar as regiões do Brasil, foram apresentadas as similaridades do ponto de vista de renda total gerada pelas famílias e fez-se um teste de análise de variância para verificar se existe diferença estatisticamente significante de renda entre as regiões do País. Neste caso, só foram considerados os Projetos de Assentamento que apresentassem renda total positiva, conforme Quadro 1, a seguir.

Quadro 1. Brasil. Teste da igualdade de médias para renda média ( $R$ \$) do Projeto de Assentamento, por Região, 2002

\begin{tabular}{|c|c|c|c|c|c|}
\hline \multirow{2}{*}{ Região } & \multirow{2}{*}{$\begin{array}{l}\text { Renda } \\
\text { Média }\end{array}$} & \multicolumn{4}{|c|}{ Teste de Igualdade de média - Anova } \\
\hline & & & Mean Square & $F$ & Sig. \\
\hline Norte & 248,00 & Entre Grupos & $2.090 .245,974$ & 157,749 & 0,001 \\
\hline Nordeste & 176,59 & Dentro Grupos & \multicolumn{3}{|l|}{$13.250,47$} \\
\hline Centro-Oeste & 275,96 & \multirow{3}{*}{\multicolumn{4}{|c|}{$\mid$}} \\
\hline Sudeste & 269,40 & & & & \\
\hline Sul & 269,43 & & & & \\
\hline
\end{tabular}

Fonte: Elaboração própria a partir do Banco de Dados do Censo da Reforma Agrária, 2002, Módulo Projetos.

O Quadro 1 mostra, além do resultado do teste de igualdade de médias, o valor da renda média, por projeto, gerada em cada região do País. Visualmente, verifica-se a diferença entre o rendimento médio das regiões Norte ( $R$ \$ 248,00) e Nordeste (R\$ 176,59) em relação ao alcançado nas regiões do Eixo-Sul (aproximadamente $\mathrm{R} \$ 270,00)$ é significativa. Esta observação é comprovada através do teste Anova, em que o resultado do teste-F na Tabela $4.3(0,001)$ indica que se deve rejeitar a hipótese de as rendas médias obtidas serem iguais para todas as regiões. Bergamasco (1997) também encontrou resultado semelhante ao mostrar que existe uma variação de renda média em termos nacional visto que as regiões Sul e Sudeste apresentaram os maiores índices de renda comparativamente à região Nordeste. Outra questão que pode estar diretamente relacionada ao diferencial de renda observado é levantada por David, Waniez e Brustlein (1997). Os autores observaram que existem duas populações diferentes de beneficiários do ponto de vista do nível de formação: os nordestinos (com aproximadamente $50 \%$ dos beneficiários analfabetos) e os outros (no qual a taxa 
1034 . Um estudo regional dos determinantes da geração de renda e construção da cidadania nos Projetos de Assentamentos

de analfabetos é inferior a 30\%). Ou seja, nos estados do Sudeste e Sul do País, os níveis de formação são superiores aos observados no Norte/Nordeste, fato que tende a repercutir no desempenho da atividade produtiva, visto que a capacidade de seus beneficiários de exercerem uma atividade produtiva é baixa (do ponto de vista de qualificação escolar).

Em seguida, na Quadro 2, foi aplicado o teste de igualdade de médias para a renda média gerada por etapa do Projeto de Assentamento. Duas questões importantes devem ser citadas: 1) De forma similar à análise anterior só foram considerados os PAs que apresentassem renda total não-nula; 2) Para os projetos que estão classificados (ou concluíram) em mais de uma etapa, o mesmo foi considerado pertencente à etapa mais avançada concluída.

Em relação aos resultados do teste, a segunda coluna contém informações sobre a renda média $(\mathrm{R} \$)$ por fase concluída. Através desta, fica clara a relação direta entre o aprofundamento das etapas com a renda gerada no assentamento; enquanto na primeira etapa analisada (PDA já elaborado) a renda média foi de R\$ 194,32 por projeto, na última etapa (PA consolidado) a renda média elevou para R\$ 480,00; comprovando, assim, a importância do desenvolvimento das etapas para a geração de renda no assentamento. Em seguida, aplicou-se o teste de igualdade de médias (Anova), em que o significado do teste-F $(0,001)$ ratifica a diferença de renda em cada etapa do PA.

Quadro 2. Brasil. Teste da igualdade de médias para Renda média ( $R$ \$) do Projeto de Assentamento, por Etapa do Projeto, 2002

\begin{tabular}{|c|c|c|c|c|c|}
\hline \multirow{2}{*}{ Etapas do Projeto } & \multirow{2}{*}{$\begin{array}{c}\text { Renda } \\
\text { Média (R\$) }\end{array}$} & \multicolumn{4}{|c|}{ Teste de Igualdade de média - Anova } \\
\hline & & & Mean Square & $F$ & Sig. \\
\hline PDA já elaborado & 194,32 & Entre Grupos & $129.772,449$ & 9,971 & ,001 \\
\hline \multirow{2}{*}{$\begin{array}{l}\text { Crédito de aquisição de } \\
\text { material de construção } \\
\text { total/parcialmente } \\
\text { concedido }\end{array}$} & \multirow[b]{2}{*}{210,75} & Dentro Grupos & $13.015,027$ & & \\
\hline & & & & & \\
\hline $\begin{array}{l}\text { Infra-estrutura } \\
\text { básica já implantada }\end{array}$ & 236,67 & & & & \\
\hline $\begin{array}{l}\text { Acesso ao } \\
\text { Pronaf/Procera total ou } \\
\text { parcialmente concedido }\end{array}$ & 247,27 & & & & \\
\hline PA consolidado & 480,00 & & & & \\
\hline
\end{tabular}

Fonte: Elaboração própria a partir do Banco de Dados do Censo da Reforma Agrária, 2002, Módulo Projetos.

O passo seguinte foi estimar um modelo econométrico que possibilitasse analisar a importância das etapas de um Projeto de Assentamento na variação da renda total gerada pelas famílias. Os resultados da estimação da equação estão contidos na Tabela 4, a seguir. 
Tabela 4. Brasil. Coeficientes estimados e o teste t do Modelo Linear Múltiplo para a Renda Total gerada pelas famílias assentadas nos PAs, 2002

\begin{tabular}{lcccc}
\hline Variáveis & Coeficiente & Desv-Pad & Stat -T & Sign. \\
\hline Constante & 178,87 & 7,39 & 24,20 & 0,01 \\
PDA já elaborado & 8,84 & 3,81 & 2,32 & 0,02 \\
Crédito de aquisição de material de & $-1,06$ & 4,87 & $-0,22$ & 0,83 \\
construção total/parcialmente concedido & & 4,19 & 1,93 & 0,05 \\
Infra-estrutura básica já implantada & 8,06 & 4,04 & 4,97 & 0,01 \\
Acesso ao Pronaf/Procera total & 20,09 & 7,38 & 3,90 & 0,01 \\
ou parcialmente concedido & 28,77 & 0,46 & $-3,74$ & 0,01 \\
PA consolidado & $-1,72$ & 4,96 & $-1,86$ & 0,06 \\
Anos de existência & $-9,22$ & 9,07 & 10,32 & 0,01 \\
Participação ativa em Associações & 93,60 & 4,89 & 15,80 & 0,01 \\
Participação ativa em Cooperativas & 77,21 & 5,53 & 15,62 & 0,01 \\
Norte & 86,41 & 7,00 & 12,34 & 0,01 \\
Centro-Oeste & 86,30 & 6,81 & 9,81 & 0,01 \\
Sudeste & 66,85 & &
\end{tabular}

Fonte: Elaboração própria a partir do Banco de Dados do Censo da Reforma Agrária, 2002, Módulo Projetos.

Sobre os resultados, é importante observar inicialmente que, com exceção da variável crédito para aquisição de material de construção, os coeficientes foram estatisticamente significantes a $10 \%{ }^{14}$. No que respeita a intensidade e o sinal dos coeficientes estimados, pode-se concluir que as etapas infra-estrutura básica já implantada, acesso ao Pronaf/Procera total ou parcialmente concedido, PA consolidado e participação em cooperativas contribuem positivamente para a determinação da renda das famílias. Algumas variáveis como anos de existência e participação em associações apresentaram sinal negativo, indicando que, no contexto de Brasil, o tempo de criação e a participação ativa em associações não colaboram para a ampliação da renda gerada pelas famílias. Sem dúvida, esta relação está fortemente influenciada pela região Nordeste - a maior em número de assentamentos - que, como visto anteriormente, distingue-se das demais regiões nestes fatores (anos de existência e formação do capital social). Em relação às variáveis de caráter regional, o resultado parece confirmar a análise descritiva feita, visto que todas as regiões apresentam, em relação à região Nordeste (variável base), uma contribuição maior na determinação da renda, dado que os coeficientes estimados foram todos positivos.

Por fim, na Tabela 5 estão os resultados referentes aos coeficientes estimados e o teste-T do modelo linear múltiplo para cada região do País. O estudo regional

\footnotetext{
${ }^{14} \mathrm{O}$ modelo foi estimado da forma robusta, evitando-se problemas de multicolinearidade.
} 
permite um diagnóstico mais preciso da realidade de cada assentamento, embora, em virtude da redução da amostra, algumas variáveis não tenham apresentado significância estatística.

Resumidamente, pode-se afirmar que nas regiões Norte e Nordeste o acesso ao crédito para aquisição de material e o PA consolidado mostraram-se estatisticamente significativos e positivos, indicando sua contribuição à formação da renda família. Para o Centro-Oeste, destacam-se a infra-estrutura básica já implantada e o PA consolidado, enquanto nas regiões Sudeste e Sul do País, o crédito de aquisição de material de construção total/parcialmente não influência na determinação da renda gerada pelas famílias enquanto que o acesso ao crédito do Pronaf/Procera é fundamental para a geração de renda na região Sudeste.

Em relação ao capital social compreendido nos assentamentos por meio da participação ativa em cooperativas, os resultados foram significativos (salvo para a Região Norte) e de forte intensidade (apresentando os maiores coeficientes estimados), refletindo sua importância na determinação da renda gerada nos assentamentos do País. Observa-se que, no Nordeste, onde em apenas 6,5\% dos assentamentos as famílias participam ativamente de cooperativas, o coeficiente estimado mostrou que nestes assentamentos a renda gerada é bem superior à gerada naqueles em que não ocorre a participação ativa dos assentados.

Por fim, no que respeita aos anos de existência do PA, o impacto foi diferenciado em algumas regiões: positivo no Centro-Oeste e no Sudeste, e negativo no Norte, Nordeste e Sul do País. Tais resultados podem causam certa estranheza; entretanto, é importante destacar que as variáveis analisadas atuam conjuntamente no processo de desenvolvimento dos Projetos de Assentamento, logo, o resultado encontrado para a variável anos de existência pode estar sendo influenciado por outra variável inserida no modelo ou algum fator externo. Recorrendo ao estudo de Albuquerque, Coelho e Vasconcelos (2004), acerca do desenvolvimento do Assentamento Dona Helena, situado no município de Cruz do Espírito Santo (PB), os autores observaram que, mesmo após seis anos de existência, as pessoas assentadas ainda não deixaram de se diferenciar economicamente dos seus vizinhos, bem como não apresentam condições de produzir sem o apoio do Estado, seja para a sua subsistência, seja para a comercialização. A suposição dos autores é que o objetivo não foi alcançado devido à péssima qualidade da terra, caracterizada como improdutiva, no caso em questão, devido à falta de adequação para a atividade agrária. No contexto deste artigo, acredita-se que os resultados encontrados podem estar fortemente relacionados à má qualidade das terras desapropriadas. ${ }^{15}$

Concluindo, não se observou similaridade nos retornos alcançados nas diferentes etapas em nível regional, devido, possivelmente, às particularidades de cada região, ou seja, às características de cada assentamento e dos atores envolvidos.

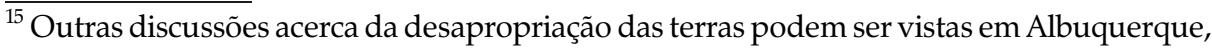
Coelho e Vasconcelos (2004), visto que não é este o foco do estudo. 
Tabela 5. Regiões do Brasil. Coeficientes estimados e o teste t do Modelo Linear Múltiplo para a Renda Total gerada pelas famílias assentadas nos PAs, 2002

\begin{tabular}{lccccc}
\hline \multirow{2}{*}{ Variáveis } & \multicolumn{5}{c}{ Região } \\
\cline { 2 - 6 } & Norte & Nordeste & Centro-Oeste & Sudeste & Sul \\
\hline Constante & 254,62 & 192,44 & 25,38 & 104,77 & 397,44 \\
& $(18,55)$ & $(24,39)$ & $(0,43)$ & $(3,31)$ & $(8,61)$ \\
PDA já elaborado & 5,91 & 12,18 & $-30,26$ & $-15,50$ & $-42,65$ \\
Crédito de aquisição de & $(0,77)$ & $(2,75)$ & $(-2,11)$ & $(-1,00)$ & $(-2,94)$ \\
material de construção & 15,48 & 3,68 & 18,14 & 2,49 & 29,43 \\
total/parcialmente & $(1,68)$ & $(0,64)$ & $(1,05)$ & $(0,14)$ & $(1,15)$ \\
concedido & & & & & \\
Infra-estrutura básica já & 13,88 & $-9,18$ & 52,30 & 43,56 & $-35,13$ \\
implantada & $(2,12)$ & $(-1,95)$ & $(3,62)$ & $(2,68)$ & $(-2,58)$ \\
Acesso ao Pronaf/Procera & 15,27 & 8,91 & 14,41 & 53,87 & 64,18 \\
total ou parcialmente & $(1,30)$ & $(2,15)$ & $(0,80)$ & $(2,82)$ & $(2,66)$ \\
concedido & & & & & \\
& 26,61 & 21,16 & 35,69 & 54,62 & 10,77 \\
PA consolidado & $(1,77)$ & $(2,18)$ & $(1,77)$ & $(1,86)$ & $(0,45)$ \\
& $-1,87$ & $-3,86$ & 26,19 & 8,03 & $-15,73$ \\
Anos de existência & $(-2,91)$ & $(-5,94)$ & $(3,96)$ & $(4,23)$ & $(-6,06)$ \\
& $-20,82$ & 5,04 & $-12,96$ & 2,76 & 24,38 \\
Participação ativa em & $(-1,61)$ & $(0,92)$ & $(-0,76)$ & $(0,13)$ & $(1,50)$ \\
Associações & 55,59 & 58,71 & 88,34 & 168,67 & 97,32 \\
Participação ativa em & $(1,28)$ & $(5,39)$ & $(2,88)$ & $(3,79)$ & $(4,96)$ \\
Cooperativas & & & &
\end{tabular}

* em parêntesis estão as estatísticas do teste-t.

Fonte: Elaboração própria a partir do Banco de Dados do Censo da Reforma Agrária, 2002, Módulo Projetos.

\section{Considerações Finais}

Este artigo procurou discutir os Projetos de Assentamentos, frutos dos programas oficiais de reforma agrária, por meio do desenvolvimento de suas principais etapas.

Inicialmente, é importante ressaltar que o desenvolvimento de um assentamento está associado a uma junção de vários fatores, o que dificulta a análise isolada de cada um; além de que existem fatores que são de difícil mensuração empírica. Sendo assim, os resultados encontrados neste estudo devem ser vistos como um instrumento a mais de conhecimento e de discussão acerca do tema. Sendo assim, este trabalho procurou analisar de forma quantitativa/qualitativa a dinâmica da geração de renda nos assentamentos do Brasil, conforme as etapas de um Projeto de Assentamento, associando, quando possível, o enfoque inter-regional à análise. 
1038 . Um estudo regional dos determinantes da geração de renda e construção da cidadania nos Projetos de Assentamentos

Por meio das informações coletadas, observou-se um número maior de Projetos de Assentamento nas regiões Norte e Nordeste quando comparada às demais do País. Tal diagnóstico pode estar relacionado diretamente ao modelo histórico de latifúndio e da monocultura ainda arraigada nestas regiões (as maiores em extensão territorial do País), o que permite a concentração de terras na mão de poucos proprietários. Não é de se admirar, portanto, que o índice de PA consolidado e de participação ativa em cooperativas encontrado seja menor nestas regiões (Norte e Nordeste), haja vista que um elemento básico para a consolidação de um Projeto de Assentamento é a formação do capital social. Conforme fundamentado por diversos autores (dentre os quais, Jara (1999) e Lazarini, Chaddad e Neves (2006)) é necessário o envolvimento de todos os atores no projeto, tanto do ponto de vista cooperativo quanto técnico, para que se alcance o desenvolvimento do PA e, consequentemente, a posse definitiva da terra. Neste contexto, o termo desenvolvimento aqui concebido deve ser entendido como um processo de transformação social que tem como finalidade a geração de oportunidades econômicas e sociais aos assentados.

Por sua vez, as regiões Sul, Centro-oeste e Sudeste apresentaram um número maior de PAs consolidados e de participação ativa em cooperativas, possivelmente refletindo a maior capacidade de organização dos atores envolvidos. Neste cenário, acredita-se que o fator escolaridade pode estar influenciado a maior capacidade de sucesso no desenvolvimento das etapas nestes assentamentos, pois, conforme citado por Buanain, Silveira e Teófilo (2001) existe uma diferença significativa no nível de escolaridade dos assentados conforme a região em que reside. Logo, como o êxito da consolidação do PA está associado à capacidade do assentado em gerir suas ações de forma independente, a desigualdade de renda pode ser explicada por um viés econômico-social.

Por fim, observou-se que a conclusão das etapas importantes do desenvolvimento dos Projetos de Assentamento são determinantes na geração de renda familiar, indicando que a emancipação do assentamento está diretamente associada ao desenvolvimento dos assentamentos.

Concluindo, espera-se que as informações filtradas neste trabalho possam contribuir para uma reflexão acerca de uma análise mais qualitativa dos assentamentos e para uma maior discussão acerca das Políticas Públicas existentes. Acredita-se que o Projeto de Reforma Agrária não deva ser realizado de forma linear em todo o País, já que, como visto, as diferenças regionais não são apenas culturais, mas também de nível de escolaridade e desenvolvimento humano e social. 


\section{Referências Bibliográficas}

AlBuQUerQue, F. J. B., COELHO, J. A. P. de M.; VASCONCELOS, T. C.. Políticas públicas e os projetos de assentamento. Estudos de Psicologia, 9(1), 81-88. 2004.

BERGAMASCO, S. M. P. P.. A realidade dos assentamentos rurais por detrás dos números. Estudos Avançados, vol. 11 (31). 1997.

BUANAIN, A. M.; SILVEIRA, J. M. da ; TEÓFILO, E.. Reforma agrária, desarrolloy participación em Brasil: Los cambios necessarios hacial el siglo XXI. In: Eduardo Robledo Rincón. (Org.). Reforma Agrária y Desarollo Rural en el Siglo XXI. México: Plaza y Valdes Edit. V. 1, p. 385-413. 2001.

CARVALHO, Y. M. C.. Os assentamentos de reforma agrária no Estado de São Paulo e a crise econômica nacional. Agricultura em São Paulo. Vol 41(3):17-37. 1994.

CMMAD, Comissão Mundial sobre Meio Ambiente e Desenvolvimento. Nosso futuro comum. Rio de Janeiro: Editora FGV, 1988.

DAVID, M. B. de A.; WANIEZ, P.; BRUSTLEIN, V.. Atlas dos beneficiários da reforma agrária. Estudos Avançados. São Paulo, v. 11, n. 31, 1997. Disponível em $<$ http://www.scielo.br/scielo.php?script =sci_arttext\&pid =S0103-401419970003 $00004 \& \operatorname{lng}=$ en\&nrm $=$ iso $>$. Acesso em 12 de setembro de 2006.

FREIRE, Paulo. Pedagogia da esperança: Um reencontro com a pedagogia do oprimido. Rio de Janeiro: Paz e Terra, 245 p. 1992.

INCRA, Instituto Nacional de Colonização e Reforma Agrária. Relatório de Atividades, 30 anos. Disponível em < http://www.incra.gov.br > Acesso em 15 de setembro de 2006.

JARA, C. J. Capital social e desenvolvimento local sustentável. Equador: Instituto Interamericano de Cooperação para Agricultura. 1999.

LIMA, E. C. de; AMORIM, C. A. M.; THOMAZ JR, A. Movimentos sociais de luta pela terra e pela Reforma Agrária na Paraíba: concepções teóricas a partir do trabalho de campo. Diez años de cambios en el Mundo, en la Geografía y en las Ciencias Sociales, 1999-2008. Actas del X Coloquio Internacional de Geocrítica, Universidad de Barcelona, 26-30 de mayo de 2008. 2008.

LAZARINI, S.; CHADDAD F. R.; NEVES, M. F. O conceito de capital social e aplicações para o desenvolvimento e estratégia sustentável. Disponível em <http:/www.capitalsocial.cbj.net>. Acesso em 18 abril de 2006. 
1040 . Um estudo regional dos determinantes da geração de renda e

construção da cidadania nos Projetos de Assentamentos

OLIVEIRA, A. U. de. A geografia das lutas nos campos. São Paulo. Ed. Contextos. 2001.

PUTNAM, R.D. Comunidade e democracia: a experiência da Itália moderna. 2. ed. Rio de Janeiro: Fundação Getúlio Vargas. 2000.

RESENDE, G. C. de. Programa de crédito especial para a reforma agrária (PROCERA): Institucionalidade, subsídio e eficácia. IPEA. 1999.

SPAROVEK, Gerd. Censo da Reforma Agrária, 2002: Módulo Projetos (Banco de dados). Piracicaba: Escola Superior de Agricultura Luiz de Queiroz (ESALQ-USP); Núcleo de Estudos Agrários e Desenvolvimento Rural (NEAD/MDA); Instituto Brasileiro de Geografia e Estatística (IBGE), 2002. Consórcio de Informações Sociais, 2005. Disponível em $<$ http://www.nadd.prp.usp.br/cis/index.aspx>. Acesso em 15 de agosto de 2006. 